\title{
Critical Thinking On the Web
}

\section{Tim van Gelder}

Department of Philosophy, University of Melbourne

Parkville VIC 3052,

Australia

E-mail: tgelder@ariel.unimelb.edu.au

Critical Thinking on the Web is a web site whose sole function is to be a useful directory of quality resources for critical thinking available elsewhere on the web. The site can be found at http://www.unimelb.edu.au/reason/critical/

\section{Background}

These days, online resources are a component of, or supplement to, almost every subject. There is a vast array of online resources available on the web, but they suffer from two problems:

(1) there is more junk than valuable material, and

(2) the material is spread across the web in a very haphazard way.

To help deal with these problems, 1 included a links page on the web site for my own introductory critical thinking classes. The page included brief annotations (usually just excerpts from the resource itself) to help the reader decide if the link was worth following. After a while the page became so extensive that it was more sensible to divide the links into categories on different pages; hence the mini-site. In 2000 , the site seemed sufficiently well-developed to be made available to wider audiences.

\section{What is on the site?}

At time of writing, the site contains a couple of hundred annotated links spread across 22 categories:

Guides: Compact guides to various aspects of critical thinking. Topics include identifying the argument of a text, and critically evaluating web pages.

Fallacies: Sites listing and describing fallacies of argumentation, such as ad hominem and slippery slope.

Online Tutorials: Sites using the interactivity of the web to provide tutorials in critical thinking.

Great Critical Thinkers: Thinkers who have tirelessly applied the tools of reason and an uncompromisingly critical attitude to the task of understanding the world, 
and the parallel task of resisting guff, propaganda, pretension, deception, pseudoscience....

Skepticism: Critical thinking applied to pseudoscience, religion, etc. A selection of the best skeptical sites.

Cults \& Quackery: Cults and quackery succeed partly because they exploit poor critical thinking capacities

Miscellaneous \& Fun: Sites that don't fit anywhere else, but shouldn't be missed.

Definitions: What is critical thinking, anyway? And what does "syllogism" mean?

Courses \& Programs: Links to online courses in critical thinking, or to web sites accompanying regular courses, or critical thinking programs

General Resources: Sites containing a wide range of critical thinking resources and links

Bibliographies: Pages containing lists of references to the critical thinking literature.

Textbooks: Links to online textbooks, or to pages describing traditional textbooks Software: Software for critical thinking, including educational packages for formal and informal reasoning.

Teaching: Links to resources useful for teachers of critical thinking.

Assessing: Resources for anyone interested in trying to evaluate critical thinking

Vendors: Companies specializing in selling products or services in the area of critical thinking.

Theory: Resources concerned with the theory of critical thinking and informal logic

Experts: Home pages of boffins ( ${ }^{*}$ Boffin, $\mathrm{n}$ : academic. Austr. colloq.) with interests in critical thinking

Institutes: Institutes, societies, centres, clubs, etc

Conferences: Conferences, Meetings, Workshops, etc.

Journals: Academic journals specializing in critical thinking

Lists \& Newsletters: Ways to fill your mailbox with critical thinking-related messages.

However, the site is continually under development. I am still coming across interesting or useful resources that have been out there for a while, and new resources are becoming available all the time.

\section{What you can do}

As a teacher of critical thinking, you might consider the following:

(a) Make use of the site in preparing your own subjects, subject web sites, etc.;

(b) Link to the site from your subject site, or make it available to your students in other ways;

(c) Send me any recommendations for additions or changes to the site. 


\section{A final word}

Critical Thinking on the Web is, to my knowledge, the most comprehensive and useful guide to critical thinking resources available on the web. As such, it is a valuable resource for the entire critical thinking community. However, I'm very much aware that it is incomplete in various respects. The trouble is that there is a limit to the amount of time I can spend trawling the web to maintain and extend the site. I appeal to everyone to help me out in this by emailing me any suggestions for additions and changes. The site can then become the community's resource rather than just my own list of favored links.

\section{Pedagogical Ideas}

\section{JoHN H. BRYANT}

Writer,/speaker in internatiional social, business and educational philosophy jn.bryant@juno.com

\section{Planned Student Participation}

1) When the syllabus is presented to the class, have a calendar of the course included with each syllabi. Each student chooses at least one date on which he/she will present a 10 minute summary of the previous session's lecture and discussion. The student will prepare this "protocol" in writing, present it to the class, and respond to questions from the other students, the professor and any guests. At the end of the summary presentation, the student submits the written summary for constructive critique, using standards and elements of critical thinking, of both the written and oral components of the work. A "Protocol" is given in each class session throughout the semester, and the students may also be invited to share in the evaluative process. [From Dr. Masao Abe, Professor Emeritus, Philosophy of Education, Nara University, Japan.]

\section{Expanding True/False questions}

2) Add a third column to all true/false and multiple guess tests. The additional option is, "I do not know". This additional option is graded as $1 / 2$ the credit of a correct response. The theory is that a student must have done something to know that they do not remember accurately, or missed the point. The grading and analysis of tests of this nature are not known to me, but they apparently yield quite meaningful data. [From Dr. John Miller, Professor of Theology, Earlham School of Religion.] 